\title{
Response Surface Stochastic Finite Element Method of Composite Structure
}

\author{
Deyong $\mathrm{CAI}^{*}$ and Fujun LIU \\ 72465 Unit of PLA, Ji'nan 250022, China
}

\begin{abstract}
Response Surface Method (RSM) has been applied to structural reliability problems successfully in many areas. Finite Element Method (FEM) is one of the most widely used computational methods, which permit the analysis and design of large-scale engineering systems. In order to obtain a reliability analysis method of composite structure with satisfactory accuracy and computational efficiency, RSM and FEM were combined by secondary development of ABAQUS. Response Surface Stochastic Finite Element Method (RSSFEM) which can solve the reliability problems of composite structure was developed. The numerical accuracy and the computational efficiency of the developed method were demonstrated by comparison with Monte-Carlo Stochastic Finite Element Method (MCSFEM).
\end{abstract}

\section{Introduction}

Fiber reinforced composite materials have been used increasingly in a variety of industrial areas including aerospace, automobile, nuclear, marine, civil and biomedical engineering $[1,2]$. This is mainly due to their high stiffness and strength-to-weight ratios, long fatigue life, resistance to electrochemical corrosion, and other superior material properties of composites $[3,4]$. However, composite laminates are significantly weak in shear, which demand special attention on the part of designers. Due to the complexity of structure, the variability in performance of a composite structure arises from material variability of each lamina is often much higher than conventional isotropic structures. A clear understanding of the structural reliability of composite structure is thus needed to fully utilize their potential in the design of various engineering components.

Engineering experience has shown that uncertainties are involved not only in the assessment of loading but also in the material and geometric properties of engineering systems $[5,6]$. The rational treatment of these uncertainties, achieved by means of probability theory and statistics, cannot be addressed rigorously when following the traditional deterministic approach. This approach, which is almost exclusively used in engineering practice even today, is based on the extreme (minimum, maximum) and mean values of system parameters. In this framework, it is implicitly assumed that the results obtained from

*Corresponding author:deyongcai@yeah.net 
a deterministic analysis are representative of all possible scenarios of system loading and strength. This is not true in most cases. It is however, sure that the deterministic approach cannot lead to an "optimum" system design [7].

Many methods have been developed to find reliability data such as the reliability index, parameter sensitivity and so on, which are based on numerical analysis as well as simulation, such as Monte Carlo simulation [8] or more advanced simulation methods [9]. For some problems, including implicit performance functions or time consuming analyses, methods such as the first order reliability method (FORM) or the second order reliability method (SORM) and MCS become very time consuming or in some cases may suffer convergence problems [10]. Therefore, approximation methods become inevitable for such problems to reduce the computing costs as well as to find the correct result for problems with convergence issues. Of the most widely used approximation methods, the Response Surface Method (RSM) has been used successfully in many areas [11]. Bucher [12] proposed an application of the RSM to structural reliability problems, and this RSM has become the most widely used [13].

It is today widely recognized that computational methods permit the analysis and design of large-scale engineering systems [14]. Finite Element Method (FEM) is the most widely used computational methods, which is especially versatile and efficient for the analysis of complex structural behaviour of the composite laminated structures [15]. Using FEM, a significant amount of research has been devoted to the analysis of vibration and dynamics, buckling, failure and damage analysis and etc [16,17].

The Stochastic Finite Element Method (SFEM) that combine structural reliability theory and FEM is a powerful tool in computational stochastic mechanics $[4,18]$. However, most of commercial finite element software are mainly to solve deterministic problems, which do not have the function of reliability calculation. To develop a stochastic finite element software of reliability analysis is complicated. It is difficult to provide useful results for practical composite structure problems in a short time. Exploring a SFEM for composite structure which not only have satisfactory numerical accuracy and computational efficiency but also be easy to realize is very necessary.

In this paper, RSM and FEM were combined by secondary development of ABAQUS. A new Response Surface Stochastic Finite Element Method (RSSFEM) for reliability analysis of composite structure was developed. The numerical accuracy and the computational efficiency of the developed method were demonstrated by comparison with Monte-Carlo Stochastic Finite Element Method (MCSFEM) with use of a numerical example.

\section{Response Surface Stochastic Finite Element Method}

RSSFEM which combine RSM and FEM is widely studied and applied in recent years [19], but there is not a ready-made response surface stochastic finite element software. To develop a new one is complicated. It is difficult to provide useful results for various practical composite structure problems in a short time. The ABAQUS software is very powerful in composite structure analysis, but it can only solve deterministic problems, do not have the function of reliability calculation.

In this paper, ABAQUS kernel was directly controlled by secondary development of ABAQUS compiled with python language. Parameterized finite element modeling of composite structure was realized. By calling the finite element analysis results, the response surface equation of limit state was established. The reliability calculation and parameter sensitivity analysis of are carried out by the JC method recommended by JCSS [20]. A RSSFEM which can solve the reliability problems of composite structure was developed. Specific analysis process is as follows: 
(1) Establish parameterized finite element model of composite structure by python language.

(2) Collect data and determine the random distribution of parameters.

(3) Take the Tsai-Wu failure criterion [21] as judging standard, use sequential RSM [22] to fit the limit state equation, given as

$$
Z=g^{\prime}(X)=a+\sum_{i=1}^{n} b_{i} x_{i}+\sum_{i=1}^{n} c_{i} x_{i}^{2}
$$

(4) Transformed the limit state response surface equation into the standard normal space, thus

$$
g(U)=a_{0}+\sum_{i=1}^{n} r_{i} u_{i}+\sum_{i=1}^{n} \lambda_{i} u_{i}^{2}
$$

(5)Take initial value of design checking point $U_{i}^{*(0)}=\left(u_{1}^{*(0)}, u_{2}^{*(0)}, \Lambda, u_{6}^{*(0)}\right)$, generally, take the mean value point of random variable in the original space, namely $x_{i}^{(0)}=\left(\mu_{X_{1}}, \mu_{X_{2}}, \Lambda \mu_{X_{3}}\right)$. By Rackwits -Fiessler algorithm, non-normal random variables were normalized, the specific algorithm shown in Fig.1. In design checking point $x^{*}$, the cumulative distribution function and the probability density function of the equivalent normal random variable are equal to the original random variable's function.

$$
\begin{gathered}
F_{x}\left(x^{*}\right)=\Phi\left(u^{*}\right) \\
f_{x}\left(x^{*}\right)=\varphi\left(u^{*}\right) / \sigma_{N}
\end{gathered}
$$

where $u^{*}=\left(x^{*}-\mu_{N}\right) / \sigma_{N}, \mu_{N}$ and $\sigma_{N}$ are the mean and variance of equivalent normal distribution function, $\varphi\left({ }^{*}\right)$ is the standard normal probability density function.

According to above equations, the approximate normal distribution function can be obtained:

$$
\begin{gathered}
\sigma_{N}=\varphi\left[\Phi^{-1}\left(F_{x}\left(x^{*}\right)\right] / f_{x}\left(x^{*}\right)\right. \\
\mu_{N}=x^{*}-\Phi^{-1}\left[F_{x}\left(x^{*}\right)\right] \sigma_{N}
\end{gathered}
$$

According to the formula, the corresponding point in the standard normal space of design checking point can be calculated.

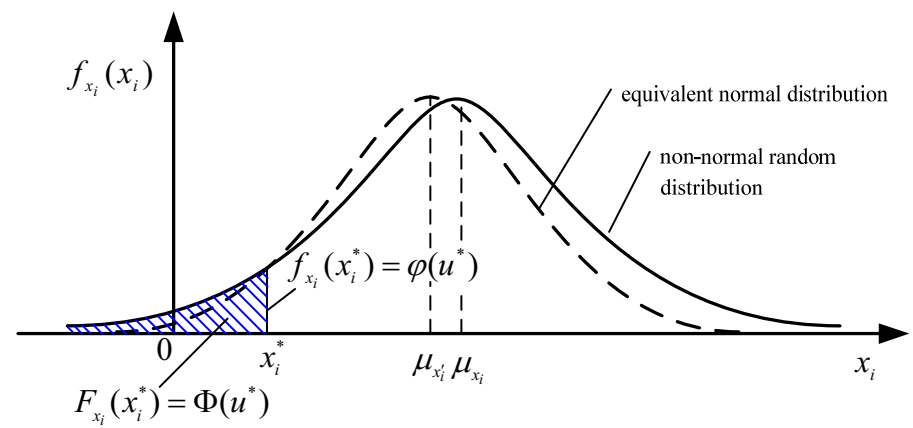

Fig.1 The equivalent normalization of non-normal random variables

(6)Take $\delta=0.3,2 n+1$ fitting points in the standard normal space can be formed.

(7)Convert fitting points into the original space. If it has been normal distribution, the original space fitting point:

$$
X_{i}^{*}=X_{i}+\sigma_{X_{i}} U_{i}^{*}
$$


(8)Calculate the limit state response value $f_{1}, f_{2}, \ldots, f_{2 n}, f_{2 n+1}$ by taking the fitting points of the original space into finite element analysis program.

(9)Take the response value calculated by finite element program into the standard normal spatial response surface fitting equation, thus

$$
\left\{\begin{array}{l}
a_{0}=f_{1} \\
a_{0}-0.3 r_{1}+0.09 \lambda_{2}=f_{2} \\
a_{0}+0.3 r_{1}+0.09 \lambda_{2}=f_{3} \\
\mathrm{M} \\
a_{0}-0.3 r_{n-1}+0.09 \lambda_{n-1}=f_{2 n} \\
a_{0}+0.3 r_{n}+0.09 \lambda_{n}=f_{2 n+1}
\end{array}\right.
$$

Equation coefficients $a_{0} 、 r_{1} 、 \lambda_{1} \ldots r_{n}, \lambda_{n}$ can be obtained.

(10)Using the JC method, the reliability index $\beta$, sensitivity coefficient $\alpha_{i}$ and the value of new design checking point can be calculated.

$$
\begin{gathered}
\beta=\left\{g\left(u_{1}^{*}, u_{2}^{*}, \Lambda, u_{n}^{*}\right)+\sum_{i=1}^{n}\left[-\left.\frac{\partial g}{\partial U_{i}}\right|_{U^{*}}\left(\mu_{u_{i}}-U_{i}^{*}\right)\right]\right\} /\left[\sum_{i=1}^{n}\left(\left.\frac{\partial g}{\partial U_{i}}\right|_{U^{*}} \sigma_{U_{i}}\right)^{2}\right]^{1 / 2} \\
\alpha_{i}=\left[-\left.\frac{\partial g}{\partial U_{i}}\right|_{U^{*}} \sigma_{U i}\right] /\left[\sum_{i=1}^{n}\left(\left.\frac{\partial g}{\partial U_{i}}\right|_{U^{*}} \sigma_{U_{i}}\right)^{2}\right]^{1 / 2} \\
u_{i}^{*}=\mu_{U i}+\beta \alpha_{i} \sigma_{U i}(i=1,2, \Lambda, n)
\end{gathered}
$$

(11) Repeat step (7) - (10) until the reliability index $\beta$ is converged.

\section{Numerical Example}

Take a glass fiber reinforced resin matrix composite launch tube of rocket as the research object. The launch tube is constructed of 12 -ply alternately to $+45^{\circ},-45^{\circ}$ bevel symmetric laminate, each of which is $0.3 \mathrm{~mm}$ thick. Fig. 4 presents laminate geometry. Consider the random distribution of $E_{1}, E_{2}, G_{12}, X_{t}, X_{c}, Y_{t}, Y_{c}$ and $S$. Specific distributions of random variables are shown in table 1 . 
Table 1 Distribution Of Random Variables

\begin{tabular}{|c|c|c|c|}
\hline $\begin{array}{c}\text { Random } \\
\text { variables }\end{array}$ & Mean & $\begin{array}{c}\text { Distribution } \\
\text { pattern }\end{array}$ & $\begin{array}{c}\text { Standard } \\
\text { deviation }\end{array}$ \\
\hline$E_{1}$ & $38.60 \mathrm{GPa}$ & $\begin{array}{c}\text { lognormal } \\
\text { distribution }\end{array}$ & $3.21 \mathrm{GPa}$ \\
\hline$E_{2}$ & $8.27 \mathrm{GPa}$ & $\begin{array}{c}\text { lognormal } \\
\text { distribution }\end{array}$ & $0.69 \mathrm{GPa}$ \\
\hline$G_{12}$ & $4.14 \mathrm{Gpa}$ & $\begin{array}{c}\text { lognormal } \\
\text { distribution }\end{array}$ & $0.35 \mathrm{Gpa}$ \\
\hline$X_{t}$ & $1062 \mathrm{MPa}$ & normal distribution & $106.2 \mathrm{MPa}$ \\
\hline$X_{c}$ & $610 \mathrm{MPa}$ & $\begin{array}{c}\text { normal } \\
\text { distribution }\end{array}$ & $61 \mathrm{MPa}$ \\
\hline$Y_{t}$ & $31 \mathrm{MPa}$ & normal distribution & $3.1 \mathrm{MPa}$ \\
\hline$Y_{c}$ & $108 \mathrm{MPa}$ & $\begin{array}{c}\text { normal } \\
\text { distribution }\end{array}$ & $10.8 \mathrm{MPa}$ \\
\hline$S$ & $68 \mathrm{MPa}$ & normal distribution & $6.8 \mathrm{MPa}$ \\
\hline
\end{tabular}

The finite element model of composite launch tube was built as shown in Fig.2. Parameterized finite element model of composite launch tube was established by secondary development of ABAQUS. Define property of the launch tube, including mechanical properties, fiber winding angle,ply thickness, number of integration points and so on. Use the 3-point Simpson integration method in ply thickness direction, so we can get material stress and strain information of every single ply.

Fig.2 The finite element model of composite launch tube

Establish the finite element model of rocket, exert rocket engine thrust at the end of the rocket, the stress during various stages of launch of launch tube was obtained by simulation calculation. Stress nephograns of composite launch tube at each stage of launching process was shown in Fig.3.

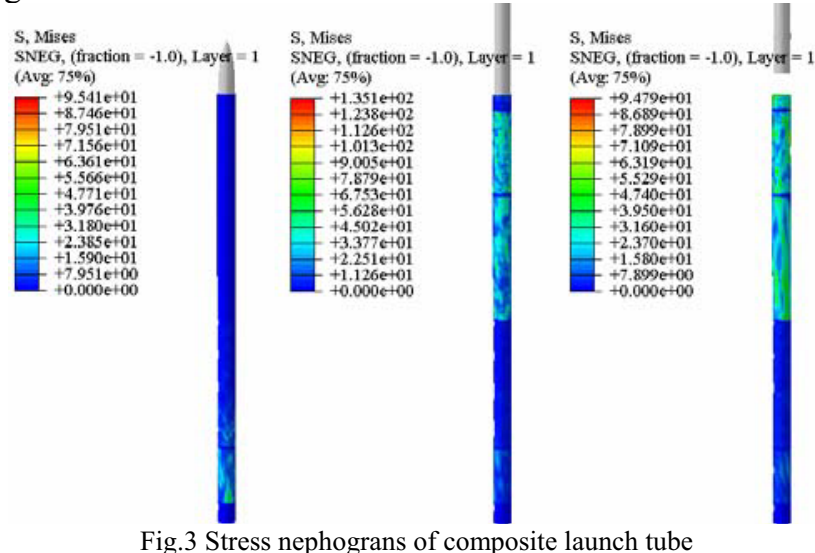

The dialogue box of random variable setting was developed by Plug-ins in ABAQUS as shown in Fig.4. Designer can set the parameters of random variables quickly and intuitively. Using RSM and JC method, the response surface stochastic finite element analysis of composite launch tube was carried out. 


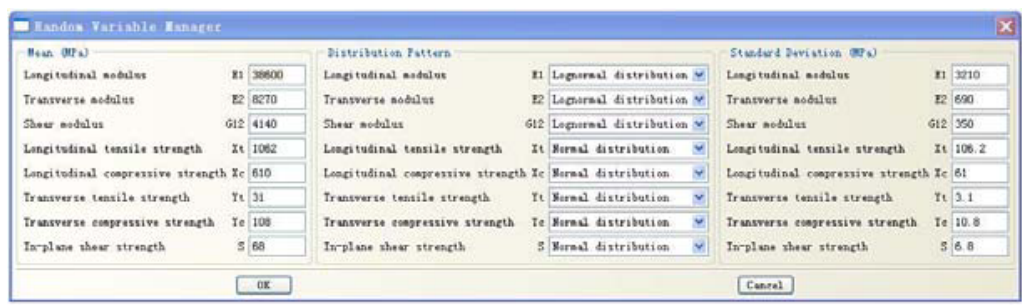

Fig.4 The dialogue box of random variable setting

The comparison on the numerical accuracy and computational efficiency between this method and MCSFEM with 1000 samples is shown in Table 2. Taking the result calculated by MCSFEM as the exact solution, the relative error of reliability index $\beta$ calculated by this method is $1.34 \%$, while the ratio of the computational time of this method to the time of MCSFEM is only1.70\%. From the above comparison, it might be suggested that the developed RSSFEM could provide a reasonable reliability prediction for composite structure with satisfactory computational efficiency.

Table 2 Results Of Reliability Calculation

\begin{tabular}{|c|c|c|c|}
\hline Analytical method & $\begin{array}{c}\text { Reliability } \\
\text { index } \beta\end{array}$ & $\begin{array}{c}\text { Relative } \\
\text { error }\end{array}$ & Computational time \\
\hline MCSFEM (1000 samples) & 2.99 & $0 \%$ & 5989 minute \\
\hline Method of this paper & 2.95 & $1.34 \%$ & 102 minute \\
\hline
\end{tabular}

\section{Conclusions}

In this study, A new RSSFEM for reliability analysis of composite structure was developed by combining RSM and FEM. A comparison with MCSFEM on the numerical accuracy and the computational efficiency was carried out. The main conclusions that can be drawn are the following:

ABAQUS kernel was directly controlled by secondary development with python language, so parameterized finite element modeling of composite structure was realized.

The RSSFEM which can solve the reliability analysis problems of composite structure was developed by combining RSM and FEM. The developed method that combines the advantage of RSM and the strong computation ability of ABAQUS software can reduce the computing costs as well as find the correct result for large-scale engineering systems.

The numerical accuracy and the computational efficiency of the developed method were demonstrated by comparison with MCSFEM with use of a numerical example.

\section{References}

1. Kumar S, Reddy K M, Kumar A, et al. Development and characterization of polymer-ceramic continuous fiber reinforced functionally graded composites for aerospace application [J]. Aerospace Science and Technology, 2013, 26(1): 185-191.

2. Fuchs E R H, Field F R, Roth R, et al. Strategic materials selection in the automobile body: Economic opportunities for polymer composite design [J]. Composites Science and Technology, 2008, 68(9): 1989-2002. 
3. Mara V, Haghani R, Harryson P. Bridge decks of fibre reinforced polymer (FRP): A sustainable solution[J]. Construction and Building Materials, 2014, 50: 190-199.

4. Mendes P J D, Barros J A O, Sena-Cruz J M, et al. Development of a pedestrian bridge with GFRP profiles and fiber reinforced self-compacting concrete deck [J]. Composite Structures, 2011, 93(11): 2969-2982.

5. Johnson B D. Engineering Uncertainty: The Role of Uncertainty in the Design of Complex Technological and Business Systems [J]. Futures, 2013, 50:56-65.

6. Endruweit A, Long A C. Influence of stochastic variations in the fibre spacing on the permeability of bi-directional textile fabrics [J]. Composites Part A: Applied Science and Manufacturing, 2006, 37(5): 679-694.

7. Stefanou G. The stochastic finite element method: past, present and future[J]. Computer Methods in Applied Mechanics and Engineering, 2009, 198(9): 1031-1051.

8. Bjerager P. Probability integration by directional simulation [J]. Journal of Engineering Mechanics, 1988, 114(8): 1285-1302.

9. Bucher C G. Adaptive sampling - an iterative fast Monte Carlo procedure [J]. Structural Safety, 1988, 5(2): 119-126.

10. Hohenbichler M, Gollwitzer S, Kruse W, et al. New light on first-and second-order reliability methods [J]. Structural safety, 1987, 4(4): 267-284.

11. Aldahdooh $\mathrm{M}$ A A, Bunnori $\mathrm{N}$ M, Johari $\mathrm{M}$ A $\mathrm{M}$. Evaluation of ultra-high-performance-fiber reinforced concrete binder content using the response surface method [J]. Materials \& Design, 2013, 52: 957-965.

12. Bucher $\mathrm{C}$ G, Bourgund $\mathrm{U}$. A fast and efficient response surface approach for structural reliability problems [J]. Structural safety, 1990, 7(1): 57-66.

13. Kim S H, Na S W. Response surface method using vector projected sampling points [J]. Structural Safety, 1997, 19(1): 3-19.

14. Mackerle J. Finite element analyses and simulations of manufacturing processes of composites and their mechanical properties: a bibliography (1985-2003) [J]. Computational materials science, 2004, 31(3): 187-219.

15. Zhang Y X, Yang $\mathrm{C} \mathrm{H}$. Recent developments in finite element analysis for laminated composite plates [J]. Composite Structures, 2009, 88(1): 147-157.

16. Rikards R, Chate A, Korjakin A. Vibration and damping analysis of laminated composite plates by the finite element method [J]. Engineering Computations, 1995, 12(1): 61-74.

17. Dey P, Sheikh A H, Sengupta D. A new element for the analysis of composite plates[J]. Finite Elements in Analysis and Design, 2014, 82: 62-71.

18. Stefanou G, Papadrakakis M. Stochastic finite element analysis of shells with combined random material and geometric properties [J]. Computer Methods in Applied Mechanics and Engineering, 2004, 193(1): 139-160.

19. Jun X U, Yingren Z. Reliability Response Surface FEM and Its Application in Engineering [J]. Underground Space, 2001, 21 (5) :354-360.

20. Nie L, Guo Y, Xu L. Reliability Analysis of Bearing Capacity of Large-Diameter Piles under Osterberg Test [J]. 2013, 5:4878-4883.

21. Tsai S W, Wu E M. A general theory of strength for anisotropic materials[J]. Journal of composite materials, 1971, 5(1): 58-80.

22. Liu Y W, Moses F. A sequential response surface method and its application in the reliability analysis of aircraft structural systems [J]. Structural Safety, 1994, 16(1): $39-46$. 